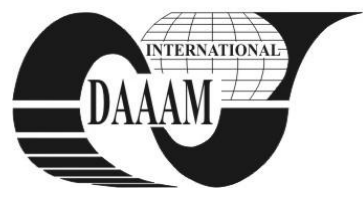

\title{
MATHEMATICAL COMPOSITE MODELS, A PATH TO SOLVE RESEARCH COMPLEX PROBLEMS
}

\author{
OANTA, E[mil]; PANAIT, C[ornel]; MARINA, V[asile]; MARINA, V[iorica]; LEPADATU, L[eonard]; \\ CONSTANTINESCU, E[liodor]; BARHALESCU, M[ihaela] L[uminita]; \\ SABAU, A[drian] \& DUMITRACHE, C[onstantin] L[uois]
}

\begin{abstract}
The paper presents original ideas regarding the actual research methods which must rely on advanced concepts and intelligent integrated instruments. Starting from the prior work which was perceived, analysed and synthesized, one can notice the progresses of the mathematical methods, the synergic effects and the important role of the computing instrument. The general 'flowchart' of a hybrid model is presented and conclusions regarding the information technology modern concepts and their increasing role are drawn.
\end{abstract}

Key words: general concepts, artificial intelligence, complex modeling

\section{INTRODUCTION}

Actual conditions are characterized by a high degree of complexity of both new problems and system of constraints.

Scarce resources, weather changes and financial problems are problems which are encountered in all the domains of science.

Since knowledge acquired in a field of science offers relevant predictive information, the problem which can be posed is how these achievements may be used in the advancement of the other domains.

An answer would be the generalization of concepts, the results being readily applied in inter-domain complex modeling, as well as in artificial intelligence.

\section{PRIOR WORK}

Each age of science uses certain instruments to manage the information, meaning to store the data, to handle the information, to perform the calculi.

These instruments impose boundaries regarding the way we perceive the world and the extent of our knowledge.

Along the history, as soon as people faced new problems they explored new solutions, some of them based on the latest technologies of that certain age. Pushing the envelope of science, new instruments to acquire knowledge were created and a new broader horizon was reached. As an example, experience in engineering was helpful to find solutions in other areas of science (Forrester, 1979).

From a historical perspective, one can notice that similarity and interdisciplinary approaches are not unusual methods of learning and they were used along the time to understand new concepts and to identify new solutions. Thus, graphical computing methods and empirical approaches evolved to analytic solutions which can be solved in different ways.

\subsection{A case study: Theory of Elasticity solutions}

One can notice that the knowledge acquired in mechanics two centuries ago has profoundly influenced the science in that age.

At mathematical level, the basic set of equations of the theory of elasticity was deduced and methods to solve it were also sketched and even completed for some simple cases.
Terms, relationships and similar laws of variation were identified in other fields of science which were reevaluated from the mechanical standpoint. As an example, 'Social Mechanics' (Haret, 2001) presents notions in the social domain using the mechanical perspective.

Similar types of equations and/or constraints as in elasticity were used in other fields of mechanical engineering, such as fluid mechanics and thermodynamics. Being very hard to find an exact solution, approximative solutions were searched.

According to that given problem, there were conceived the most accurate solutions and the according set of constraints to be satisfied (proper boundary conditions), leaving some other constraints (considered not important for that particular phenomenon) unsatisfied. These solutions could solve classes of problems in a satisfactory way, but they were not general.

Another direction was to minimize the errors using various strategies, starting from a general form proposed for the theoretical solution. A method was to apply some boundary conditions for the computing domain and, usually, systems of equations which can be readily solved result. Another method was to divide the computing domain into subdomains where particular solutions are conceived. Finally composite solutions across the whole domain are designed.

Similarity with other phenomena governed by the same equations and principles was an important inspiring environment. The most important methods resulted from the similarity between the mechanical and electrical phenomena. These ideas were used to develop both theoretical solutions and experimental methods and the according equipment. Moreover, an analytic solution of a certain problem could be modeled as a circuitry defined on an analog computer, so the technical problem may be expressed as an electrical equivalent system.

Staring from this pool of ideas, structural engineering evolved quickly and rapid progresses were recorded in both theoretical and experimental fields.

There was a decisive factor which accelerated the progresses in all the fields of science and, of course, in mechanical engineering.

\subsection{Importance of the computing instruments}

One can notice that the computing instruments are the most important mean of progress. They influence the methods to investigate the reality, which are the basic 'fabric' of the models.

Even from ancient times people imagined methods to measure and to compute which offered technological strengths in astronomy, construction of large stone structures, calendars and navigation. Aside from the computing means, of a particular importance were the methods to store the information and also to encrypt the sensitive knowledge. Several methods were imagined, some of them being suggestive even nowadays.

The importance of the computing aspects is also revealed by the calculus contests organized hundreds of years ago, which lead to new solving methods. 
Once the computer was invented as an instrument to solve the problems in the nuclear research and industry, as well as in astronautics, the paradigm of progress was changed and rapid changes were noticed (Goldberg, 1991). One can notice that complex studies rely on mathematics, modern algorithms and computer programming (Peterlik, 2010).

\section{ORIGINAL SOLUTION}

A method to solve the complex nowadays problems, is to conceive versatile hybrid models which use various sources of information, being integrated by the use of an original software application.

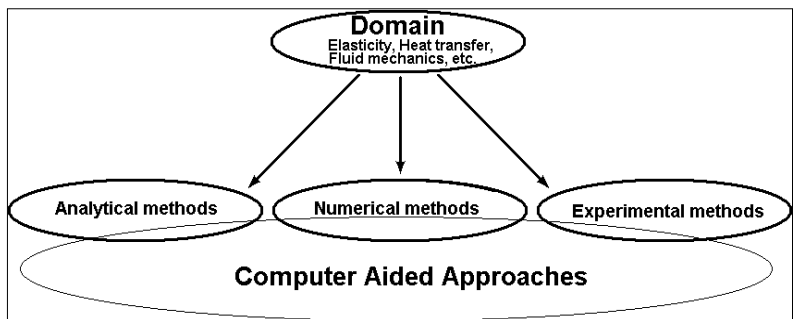

Fig. 1. Regardless the field of engineering, integration may be done using original software applications

The branches of the model may be integrated from several points of view, the most basic being the mathematical level, where the composite methods and solutions are designed in a unified manner.

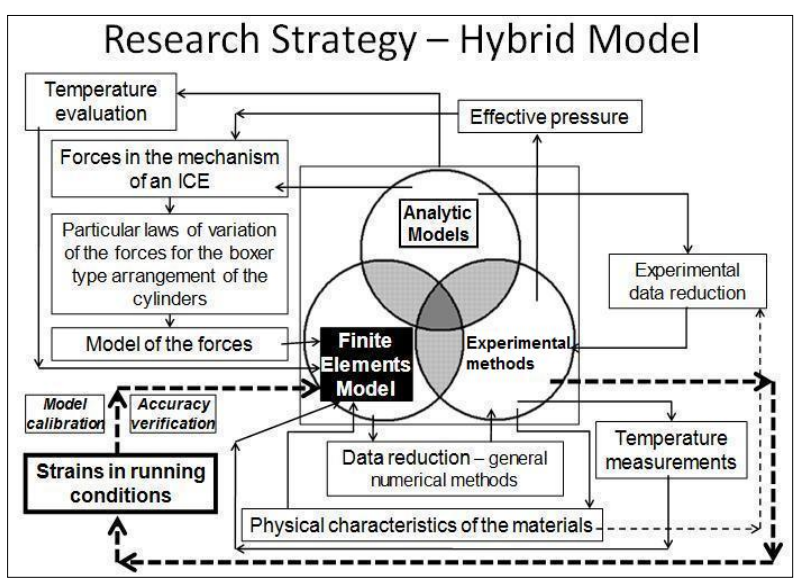

Fig. 2. Composite mathematical methods integrated in a hybrid model within a complex research study

The figure above presents the general 'flowchart' of a hybrid model which consists of analytical, numerical and experimental components. The study was dedicated to the calculus of the strains and stresses in the cylinder block of a naval engine.

The numerical results of the research were used to solve optimization problems and to evaluate the behavior of the engine in some constrained conditions. The most important theoretical result was the identification of a strategy which integrates different components (analytic, numeric and experimental) using original software applications. This hybrid modeling concept was employed as an inspiring environment to solve, at a later stage, several other complex problems.

\section{CONCLUSION}

Nowadays knowledge management was a long run concern of the authors (Oanta, 2004; Oanta et al., 2011). Using strategic development concepts based on composite mathematical models several problems were solved in elasticity (Oanta \&
Nita, 2009) and business intelligence (Oanta et al. 2007). This vision regarding the global problems unified in some few basic disjunct matters lead to the creation of some general software instruments which can be used in several fields of science.

To conclude, taking into consideration the evolution of science, once the new instruments to acquire knowledge are created, they modify the world not only technologically, but in a more intimate degree, at that particular level where new concepts are conceived, tested and developed.

Nowadays, the progresses in information technology create a new paradigm in acquiring knowledge. Moreover, by creating new information technology general concepts which can solve composite mathematical models, profound and rapid progresses can be achieved.

\section{ACKNOWLEDGEMENTS}

Several of the ideas presented in the paper are the result of the models developed in the framework of the MIEC2010 bilateral Ro-Md research project, Oanta, E., Panait, C., Lepadatu, L., Tamas, R., Constantinescu, M., Odagescu, I., Tamas, I., Batrinca, G., Nistor, C., Marina, V., Iliadi, G., Sontea, V., Marina, V., Balan, V. (2010-2012), "Mathematical Models for Inter-Domain Approaches with Applications in Engineering and Economy", MIEC2010 - Bilateral RomaniaMoldavia Scientific Research Project, under the supervision of the National Authority for Scientific Research (ANCS), Romania, that is the follow-up of the ID1223 scientific research project: Oanta, E., Panait, C., Nicolescu, B., Dinu, S., Pescaru, A., Nita, A., Gavrila, G., (2007-2010), "Computer Aided Advanced Studies in Applied Elasticity from an Interdisciplinary Perspective", under the supervision of the National University Research Council (CNCSIS), Romania.

\section{REFERENCES}

Goldberg, D. (1991), What Every Computer Scientist Should Know About Floating-Point Arithmetic, ACM Computing Surveys, Vol. 23, No. 1, March 1991, 5-48, ISSN 03600300

Haret, S. (2001), Social Mechanics, 100+1 GRAMAR Publishing House, ISBN GR-400028, Bucuresti

Forrester, J. W. (1979) Principles of Systems, 'Technical' Publishing House, Bucharest

Oanta, E.; Barhalesu, M. \& Sabau, A. (2011). Management of change based on creative inter-domain syntheses, Proceedings of MTC2011-The 7th International Conference Management of Technological Changes 'Sustainable Development trough Technological Change', September $1^{\text {st }}$ $-3^{\text {rd }}, 2011$, Alexandroupolis, Greece, Book 2, pp 589-592, ISBN: 978-960-99486-1-6, ISBN (Book 2): 978-96099486-3-0

Oanta, E.; Nita, A. (2009). An Original Method to Compute the Stresses in Applied Elasticity, Journal of Optoelectronics and Advanced Materials - Rapid Communications (OAM$R C)$, Vol. 3, No. 11, November 2009, pp. 1226-1230, ISSN: 1842-6573

Oanta, E.; Odagescu, I. \& Tamas, I. (2007). Management Instruments which Use Probabilistic Approaches. Case studies, Proceedings of MEI2007 - The 3rd International Symposium on Management, Engineering and Informatics, July 8-11, 2007, Orlando, Florida, USA, ISBN-13: 978-1934272-14-5, Nagib Callaos, William Lesso, D. Dale Zinn, Daisuke Tominaga, Shigehiro Hashimoto, Sheng-He Huang, Meda Truta (Ed.), pp. 384-389, International Institute of Informatics and Systemics, USA

Peterlik, I.; Matyska L. \& Filipovic J. (2010), Haptic Interaction with Complex Models Based on Precomputations, Advances in Haptics, ISBN 978-953-307093-3, Mehrdad Hosseini Zadeh (Ed.), InTech, April 2010 